\title{
DISCOURSE ON E-MAIL IN USE
}

\author{
Mats Edenius \\ Centre for Information and Communication Research \\ Stockholm School of Economics \\ Stockholm \\ Sweden
}

\begin{abstract}
This paper, which is drawn upon three empirical studies, focuses on key features of the discourse around e-mail in a professional context. The present discussion is inspired by Michel Foucault's concept of disciplinary power. The paper illustrates how using e-mail maintains an analytical space, a discipline of classifying, measuring, comparative order, experiments and small penalty systems. Using e-mail in the context of this discipline, however, has problems. One such problem, illuminated in the paper, is overload. It is proposed that, as a result of the large amount of e-mail, users either let themselves be encompassed by the same disciplinary power that leads to the overload problems, or they start a syntactical reorganization of how to organize so much e-mail.
\end{abstract}

\section{INTRODUCTION}

in any society the production of discourse is at once controlled, selected, organized and redistributed according to a number of procedures whose role is to avert its powers and its dangers, to master the unpredictable event (Foucault 1971, pp. 10-11).

We are said to be in a knowledge economy, where value stems more from professional workers and how they are organized than from physical products (Bell 1974; Drucker 1973; Nelson and Winter 1982). Strengthening this notion, we can also see an effusive enthusiasm for the various techniques of managing, generating, disseminating and integrating knowledge to improve business per-

The original version of this chapter was revised: The copyright line was incorrect. This has been corrected. The Erratum to this chapter is available at DOI: 10.1007/978-0-387-35634-1_28 
formance (Cross and Baird 2000; Davenport and Prusak 1998; Stewart 1997). Many of these techniques coincide with different kinds of information and communication technologies (ICTs). One such technological device is e-mail. E-mail is today a well-established technology for communication. It is also the most used tool in Internet and intranet systems. It is a technology we can hardly avoid if we want to participate in contemporary Western professional life.

The stated ambition of information technology finds its echo in the enlightenment dream of an educated society, wherein all knowledge is available to the least individual (Poster 1990, p. 72). It is, therefore, not a coincidence that many researchers in the computer networking field link their research to concepts such as democracy, power relations, freedom and equality (i.e. , Sproull and Kiesler 1991). The issue of how e-mail can get us closer to this modern utopia also has been a central issue in research about e-mail (Bikson et al. 1989; Cecez-Kecmanovic et al. 1999; Child and Loveridge 1990; Dubrovsky et al. 1991; Feldman 1987; Hiltz and Turoff 1978; Kiesler 1986; Kiesler et al. 1984; Rice 1990; Siegel 1986; Rom and Pliskin 1999). In summarizing the research in this field, one of the main issues, in line with Habermas' (1979, 1984) theory of the speech act and his three key themes of social science (labor, language, and power), is if and how e-mail can make it easier to maintain a kind of communicative action where the good argument will come out from a rational discussion of more or less emancipated workers.

However, what these studies have in common is that they mainly regard email as a mechanical tool to transmit information as well as knowledge. Knowledge is seen, as Latour (1997) expresses it, as an "immutable mobile." The research neither puts into focus the myriad of discursive practices (i.e., practices of talk, text, writing, cognition, argumentation, or representation generally) that can be linked to using different ICTs and e-mail specifically, nor does it highlight that discursive practices and their discursive formations are active and productive and are central instances of new knowledge clusters and new categories of significance (Chia 1996; Goodman 1978; Kallinikos 1996; Power 1997).

\section{AIM OF THE PAPER AND THE THEORETICAL OUTLINE}

In this paper, knowledge and power are not regarded as a given resource preexisting the discourse that constitutes it. Rather the opposite. Instead of email being a tool where knowledge is regarded to exist regardless of the container it happens to occupy, it is seen as a complex system of discursive practices for giving meaning to the world, organizing social processes, and 
naturalizing or normalizing such structures and meanings, rather like Foucault's (1971) idea "to master the unpredictable event."

The overall aim of this paper is to shed further light on what e-mail means and how it is organized. More specifically, the aim is twofold. First, to illustrate how features of the discussion around e-mail can be regarded as disciplinary power, a power that generates its own knowledge and its own results. It will be argued that one such result of using e-mail is overload problems, which brings us to the second aim of the paper: to suggest that in our ambition to solve the problem of overload we can find one explicit discourse stuck in disciplinary power, but glimpse another discourse belonging to another discipline. For illustrative purposes, the paper draws upon three empirical studies of e-mail systems in use in three different organizations.

This paper is inspired by Foucault's notion of discourse and knowledge creation seen as discursive formations (Foucault 1966, 1972). Foucault's works are frequently linked to the concepts of archaeology and genealogy (Deleuze 1988; Dreyfus and Merquior 1985; Hoy 1986; Rabinow 1983; Sheridan 1980). These two concepts are not to be regarded as separate. It is not a question of dividing Foucault's work into early or late production. Instead we can see Foucault's work as different breakpoints where power and discourse are central (Deleuze 1988). The concept of archaeology in Foucault's writing could be characterized as a method of analyzing discourses. Discourse in this context may be described as how things are represented. Foucault $(1966,1972)$ is neither interested in what kind of thoughts and ideas may be behind a certain description, nor whether certain discourses correspond to reality. He focuses on how and when different discursive formations are produced and argues that discourses have a historically specific character constituted by different strategies. Foucault calls this discursive power (see Clegg 1998, p. 30). Foucault also argues that discourses found dominating in different areas are to be seen as closely linked to the diffusion of different technologies in more local institutions (see also Merquior 1985). This is what Foucault, embarking on his genealogy of Western thoughts, convincingly illuminates in his books Madness and Civilization (1965) and Discipline and Punish (1977). He shows how the earlier division of people having or not having the plague has continued in other forms later on with other objects. During the nineteenth century, many techniques to measure, control, and normalize were devised in schools, prisons, industries, and armies. In these projects, he argues, the individual is an effect of power, but at the same time a place for its articulation (see, for example, Gordon 1980, p. 98 ff). The individual, constituted by the power, is at the same time its intermediary and instrument due to many different techniques and discursive practices (such as the dividing technique) that the power has encapsulated the individual (see Deleuze 1988; Hoy 1986; Sheridan 1980). 
One famous example is when Foucault (1977) links Jeremy Bantham's famous Panopticon with disciplinary power. Prisoners in a panopticon are located and divided in such a way that they are seen by the guardian one by one, themselves being unable to see when they are watched and when they are not. Because the prisoners are unaware of when they are observed and when they are not, after some time, they internalize the forms of control to which they were subjected by the disciplinary gaze and disciplinary power. But it is important to note that Foucault is not under the illusion that the prison works as a result of a program through the image of the grand strategist and his plan. The prison rather works for its own failure. The prison should not be seen only as an institution, which normalizes. The discipline and normalization should rather be seen as many different practices, going on both inside and outside the walls of the prison. Following the notion of Foucault, there is no reason to expect that the discursive formations around prisons will remain contextually and historically stable, and there is every reason to think that they will shift. It is, therefore, not a coincidence that Foucault $(1977$, p. 216) calls the Panopticon an event in the "history of the human mind." The coherence of the phenomena described is to be found in the order of the technology itself (like the dividing technique at schools and in prisons), rather than in some other order (see Gordon 1980, p. $249 \mathrm{ff}$.). The effect can differ from time to time and this is what makes such an analysis interesting. It is, for example, possible for the school and its discursive practices (like grades and titles) and different normalization processes to work from different initial discourses: to foster the children, to make them become individuals, to become well-educated for a future job etc.

From this quite theoretical opening, but without getting too involved in a discussion about Foucault's complex treatment of general forms of rationality pertinent to the study of power and discursive formations of knowledge, this paper's analysis starts from a much more modest notion. Inspired by Foucault, I will argue that the discursive practices around e-mail can be seen as a special procedure that limits and controls discourses. I will illustrate that the production of the discourse around using e-mail, as an ordinary speech form, can be interpreted as a result of disciplinary power, a discourse linked to a specific context to achieve a special way of thinking and acting. The network also works for its own failure. The more active the users are, the more e-mail they will get. Overload problems occur. At the end of the paper I will suggest that, in the context of the large amount of e-mail in circulation, we can glimpse fragments of another discourse around e-mail that could be not only an exploration of why this kind of materialized ambition to reduce the overload problem does not work so well in practice, but also illustrates the fragility and randomness of the key features of the discourse around e-mail.

Aside from this focus, this paper has certain limitations. Little will be said about how the written language as such is represented and its results. The 
technique of representations exemplified in the text is, of course, not unique to e-mail. It could be applied to many other technologies as well. E-mail seems to be just one technology where the power of representation has been exaggerated and hyperbolized by different techniques of representation.

The mode of thinking in this paper favors the illumination of organizing as a generic process of world-making (Chia 1996, 1998). In other words, the ontological commitment shifts to a becoming-realism instead of the more conventional being-realism. This article is based on a becoming-realism perspective with discursive practices around e-mail in focus. In my analysis, I neither wish to overlook that people know what they are doing and why they do it, nor to suggest that the conventional studies are not fruitful; but maybe go a little bit beyond the more standard borders found in conventional research about e-mail.

My perspective may be criticized - in line with criticism of Foucault's works in general - as being too negative in its analyses, where almost everything is regarded as a result of power and discipline (Dreyfus and Rabinow 1983).

Conscious of these limitations and weaknesses, I will discuss and illustrate how an e-mail system could be regarded as a technology that encompasses different programs coinciding with different discourses, a special way of saying and doing, that can be linked to disciplinary power. From this, I will turn to some of the main results of using e-mail and how the users try to master some of its unprogrammed effects.

\section{NOTES ON THE METHOD AND CASE COMPANIES}

The argumentation in this paper is supported by three different case studies. The cases are based on tape-recorded and transcribed interviews. The interviewees were asked to discuss how they used e-mail and its quality. Foci were on general aspects of using e-mail and not in the context of the backgrounds or organizational context of the person. The interviews included questions like:

- How do you use e-mail?

- What do you get out of it?

Ten interviews were conducted with people working in the central office of a bank, and ten with management consultants working in a very small organization. The companies were chosen because of the inherent understanding of being normal in their use of e-mail. All of the interviewees had used e-mail for many years. The interviews were conducted in 1996. These two cases were complemented, in 2001, 10 ten interviews with administrative personal working 
in an insurance company. The case studies from 1996 were complemented in order to broaden the empirical material and to see if any differences could be found between them that could be attributed to the time gap. The interviews in the insurance company also proceeded in a more ambitious way than just meeting people for the first time to discuss how they use e-mail. The interviewees were given a form for one week and asked to record how much email they had sent and received. They also could note how much time they spent on e-mail, when and where, and make their own comments. After one week, the interviews were conducted. The same questions were used as in 1996, with one exception: they were also asked to share their experience in dealing with the amount of incoming e-mail, how they organized it, and if they saw it as a problem. The reason was that I could see a higher quantity of incoming and outgoing e-mail in these interviewees. All three companies appreciated the system very much, but complained about the sheer amount of e-mail.

It is important to note that the aim with the empirical material was not primarily to verify any clear theories or hypotheses (the numbers of interviews and cases are too limited for that), but to give examples and illustrate the argumentation in this paper. The method is, therefore, to be regarded as abductive (Alvesson and Sköldberg 2000; Hanson 1958). I agree that the reliability of my results can be questioned; hopefully such a strategy may increase the fruitfulness (cf. Eco and Sebock 1984).

\section{E-MAIL, ANALYTICAL SPACE, AND OUR WILL TO MAINTAIN HIGH ACTIVITY}

When participating in an e-mail network, the interviewees say it is important to know that the e-mail will be read, otherwise there is no point in sending it (if the purpose is not just auto-communication, cf. Broms and Gahmberg 1983). This can be seen as a truism but still an important feature of an e-mail network.

I try to answer my e-mail as rapidly as possible and not to make it too complicated. Everything is built on the principle that everyone opens their mailboxes, otherwise it does not work (Consultant).

To control the process is also to let other people work for you. In other words, you must incorporate relevant features from the periphery and make these features work for you. The interviewees also say that e-mail is efficient because they can get in contact with their colleagues quickly. The system makes it easy to maintain this kind of efficiency because it makes it easy to know which colleagues are active or not, expressed by another consultant: 


\begin{abstract}
I know precisely which of my colleagues read my e-mail, due to the function of receipt. I usually save and use this function to get to know how fast I can expect to be answered the next time I send an e-mail. It takes one and a half to three weeks until everybody except three have read it. It is an analysis I can bring with me to different meetings to get other people to use the system more frequently.
\end{abstract}

The consultant had started as a habit to follow up and compare how many of his colleagues read his e-mail. As an efficient e-mail user, he knows from whom he can expect to get a quick answer. It is no good sending an e-mail to someone who is not going to read it. The person who was supposed to get the email will never know that he got an e-mail (I will soon come to the sanctions of getting people to use the system) because he never turns the computer on. Thanks to the system, the person can find out the kind of communication he can get on with, instead of being interrupted by an ordinary discussion or getting into a discussion he would like to avoid.

Advances in information technology have extended the reach and range of what can be called the big-brother-sees-you ambition of management, well discussed in other literature (Zuboff 1988). But here we see more peculiar results of practicing e-mail. Described by Foucault (1977) as change in the society from Antiquity, where the problem with architecture was to render accessible to a multitude of men the inspection of a small number of objects, to the modern age of Panopticon; to procure for a small number the instantaneous view of a great multitude. Its aim was

to establish presence and absence, to know where and how to locate individuals, to set up a useful communication, to interrupt others, to be able at each moment to supervise the conduct of each individual, to assess it, to judge it, to calculate its qualities or merits. It was a procedure, therefore, aimed at knowing, mastering and using. Discipline organized an analytical space (Foucault 1977, p. 143).

Foucault uses the concept of discipline as pointing out a special procedure that limits and controls discourses. He argues that a discipline is what makes new statements, new propositions, possible. But discipline is not simply all that may be said to be true about something. For a proposition to belong to a particular discipline, it must refer to a specific range of objects (see also Sheridan 1986, p. 126 ff.). In the e-mail case, the gaze does not come from a guard in the tower in the middle of the prison. In the e-mail network, everybody 
can be a guard, guarding others as well as themselves. If we see discipline as that which makes new statements and new propositions possible, we can say that, thanks to the analytical space, a form of control can be maintained and this kind of control might be regarded as fully normalized by the users. We can say that the consultant in the example above, thanks to the analytical space, used the system to conduct experiments to discover a formula to make the system more productive. This kind of experiment is almost necessary to get a network to work as smoothly as possible.

The user can know in advance or make a prediction about how and how quickly his e-mail will get a reply (in the same way as a guard in a prison can manipulate and conduct experiments with the prisoners). The receiver of the email must discipline himself too. It is a continuous discipline that encompasses a user, tending to continuous comparison and evaluation of his own activity. The man in the example can compare his activity to that of others, which he can bring with him to meetings, etc.

This was even more apparent in the following example from a woman who worked in the bank:

I think that e-mail is a very good tool to reach people who are hard to get in touch with by phone. I felt sad about people who do not read their e-mail. Then I started to cheat my colleagues a little bit. I started to send out important information only by e-mail. Afterwards I phoned some of them and asked if they had read my e-mail. They said no-which I already knew from the e-mail system - and I told them about some important news they missed or something like that. After that they started to read their e-mail more continuously. I reduced the mean reading time from two weeks to three days. However, there were some of my colleagues who did not answer my e-mail at all. Then I sent out an important report and wrote at the end of the report that everybody who had read to this point could phone me the same day and I would buy them biscuits for the afternoon tea. There were some of the slow readers who phoned me.

She used the system almost entirely for experimentation in this case. She said that she had cut the mean reading time from two weeks to a couple of days. The information can be represented in a compact and manageable form, thanks to the written language and due to the well-administrated and stored information.

The woman in the example discovered something by sending out e-mail, getting it back after a while, and drawing conclusions. Almost everyone using e-mail has received e-mail with a "smashing" title (subject), for example, "Cakes 
today." She does not have to spend time calling someone who is hard to reach as she probably had to do before they installed the e-mail system. The time here is not, in this sense, most important. What she did was to present the information in an abbreviated form. The reader did not have to read a full text to find out if it was an interesting e-mail, worth a reply. The reader got that information in just one sentence. From the quotation we can see how the structure of the language, in combination with how language is represented, in an e-mail system results in a rapid exchange of e-mail. By representing language in a hierarchical order, the users can select what is important or not (see for example Königer and Janowitz 1995) and we can only imagine what the next smashing title will be to get through with her message.

The analytical space is also useful when I tried to find people to interview for this study. It is very easy to locate people who do not use the system very frequently. Through the analytical space, which is a result of the machinery, the people who use the system very often locate people who do not.

Another example, belonging to the same discipline, will be found in the strength of letting users structure incoming and outgoing e-mail by using filters, user-profiles, and different folders (see, for instance, Bälter 1998; Malone et al. 1987). We could say it is a strategy to decentralize a kind of dividing principle of different users to every individual user. It has to do with economizing in space and time. Abbreviating information makes it easier for the mind and body to handle (Cooper 1992). Classification and counting come into focus. A large number of people, a large number of e-addresses, can be closely packed in physical space and easily transferred to the smaller space in the folders. This is not only a basis for control; the abbreviated representation of the world in classes and names enables e-mail users to see more clearly and more quickly (see also Cooper 1993, p. 226), or expressed in Foucault's words (1977, p. 216) when he encapsulates the modern society, "procure for a small number, or even for a single individual, the instantaneous view of a great multitude." A quick glance is enough to figure out the relevant e-mail, which makes it easier to for the mind and body to handle a lot of e-mail.

To sum up, in this part of the paper, I have illustrated that the e-mail system provides the users with a matrix, which enables the individual to be linked to a taxonomy that involves practices of recording and comparison. Using e-mail constitutes systems of recording, classifying, and measuring, and in doing so it provides the basis for the operation of government. The result of the analytical space is occasionally that the user avoids using the system. Active users can count qualities and merits; they can uphold a scheme of competitive order and become even more active and productive. The users maintain the discipline of an analytical space. In an e-mail system, a maximum of intensity can be reached with the largest size of group as possible. The more active you are, the more e- 
mail you send, the more electronic meetings you participate in, the higher the efficiency will become. At the same time, the more disciplined you will become. It is an occurrence where the disciplinary power lives in symbiosis with docile bodies.

The discursive formation around e-mail also covers other discussions. Another characteristic is that a small penal system exists. Drawn from Foucault, it can be said to enjoy a kind of legal privilege with its own laws; it has particular forms of judgement. The penalties in e-mail systems can take different forms. The most obvious is the premise which states that if you do not participate in the network, you do not belong to the group. It seems that the users, independent of their activity in the systems, are reminded that they should use the system more frequently.

In the case studies, many people said that they encourage other people to use the system or to use it more frequently. It looks like the users, independent of their activity in the system, will be reminded of how important it is to use the system. I observed the following part of a discussion during a coffee break in the consultant firm:

A senior consultant told the others how another consultant, as a habit, used not to empty her e-mail box during the weekends. The consultant said that she had not been in the head office for a whole week (she had been out with her clients). She gave that reason to defend herself for not having read her messages. She told me that one of her colleagues had sent her an important email during the week; on Monday the week after, the colleague asked her why she had not read his e-mail. She told him that she had been out with her client but excused herself by noticing that she had answered his e-mail the same morning (which the colleague had not realized). The colleague became irritated and said that she had the technology to answer e-mail independent of time or space. He nearly reprimanded because she had not answered the e-mail during the evening. The senior consultant said, "I have got a computer at home, but I feel that I do not want to work at home, I should be free at the weekends, I am fed up with turning that devilish computer on all the time." Another consultant said a moment later, "Yes, if you don't answer your e-mail immediately, then your colleagues start to wonder if you are on holiday."

At the same time, it is important to notice that these small penalties also could be linked to the possibility of missing important information. As noted by two people from the insurance company: 
I read my e-mail before I leave the house, in case there may be something important in the box. I also read my e-mail as soon I get to work...if I don't read my e-mail, I get a strange feeling...that I'm updated enough.

I feel stressed when I've not opened all of my e-mail. I know that this is different from person to person, some of my colleagues do not open their e-mail all the time, but I feel that there may be some important one that I must know to get on with my job in an efficient way. So I open my mailbox when I arrive; it is very stressful, but they are often very relevant. As one example, I was involved in several projects some time ago, $I$ had booked meetings from 9 in the morning to 5 in the afternoon. I thought I could come in at 8 in the morning to open and work with my e-mail. I found that I had got too much email to handle in this short time, and some of the e-mail was urgent, so I tried to print them, but the printer was broken, I became very stressed out.

Members of the network find themselves being watched by others. They say that they will be sneered at if they do not open their mailbox often enough. But it is important to recap that this sanction is connected with the possibility of missing important information, of not being updated, not remaining a member of the group. The organizing process happens in a context of circulating insecurity; not only because of the possibility of being misunderstood, of not finding a place to focus on, but also there is a nagging insecurity (if only small) of becoming sidelined. At the same time, participation in the network facilitates the possibility to get important information, as an interviewee said, "You never know what is in your e-mail. There could be a thunderbolt." These mechanisms seem to ensure high activity.

We can also see that the penalties, which are the result of the disciplinary system should be corrective. Foucault (1977, p. 179) does not primarily mean that the penalty should be used to get things to change. The main point of the penalty is to prevent people handling things in a different way. The people in a network are always seen, the network's architecture is a medium for this correcting mechanism. The users will always be reminded about the possibility of missing important information, and that someone else always sees whether you are a virtuous user. But the machinery gives people another possibility as well; spam and annoying advertisements could be tracked. 


\section{THE DISCOURSE AROUND E-MAIL STRIKES BACK}

Overload is maybe the most used concept linked to negative consequences with e-mail, both for the individuals and the efficiency in the organization, and the problem is increasing (see Business Week, March 1, 2002). In this section of the paper it will be argued that the overload problem is the natural result of the disciplinary power linked to using e-mail. Further, I will maintain that to solve the problem of overload we can still be in the discipline of an analytical space, as a certain statement or discussion linked to disciplinary technologies, which in turn is connected to new problems. To solve the problem of overload, users seem to be stuck for different dividing practices to maintain a kind of prioritizing system, still being encompassed in the same disciplinary power that leads to the overload problems and which seems to be connected to serious practical problems. But, at the same time, users confronted by e-mail piling up also seem to start a syntactical reorganization of what e-mailing is all about.

We can see that to be active in the network raises the question of exhausting your time. People can make a lot of contacts with other people in a short time compared to other technologies or oral communication. The actors say they can do more things, synchronize these things, and carry them out in a productive sequence. They regard e-mail as an efficient tool.

But paradoxically, all this happens in machinery where it is impossible for all users to answer all e-mail, because they get too much. The more active they are, the more e-mail they will get. Sooner or later the overload problem turns up. At the same time as the users say that they get rapid contact thanks to e-mail and get control over their communication, everything in one place, briefly said to become accessible efficiently thanks to e-mail, the system also generates chaos, a mess, and insecurity.

There are currently two different principle strategies to more or less try to solve this problem, both strategically available through e-mail technology. The first solution to the problem is partly to use different kinds of intelligent agents (Motiwalla 1995), to increase the possibility to order the incoming outgoing email (see Bälter 1998; Hall 1988). These prioritizing systems, however, can give rice to serious problems. As Motiwalla (1995, p. 23) stresses:

The success...in managing users' time is highly dependent upon the system not assigning a high priority to low priority messages and vice versa. The first error could cause the users to hate e-mail, while the latter could cause information overload.

Motiwalla stresses that the system demands a lot of support and follow-up to achieve its purpose. Added to this, he points out the risk that users will start 
to manipulate the system for their own wishes. Another conclusion is that the amount of e-mail does not necessarily decrease due to the intelligent agent. At the same time the agent is implemented, you have opened a lock for even more relevant post. I found this in my empirical material as well. In the insurance company, everyone works in a milieu where they could install a prioritizing system, but they didn't. As one user said briefly, "It is too complicated and doesn't work in practice."

The second strategy to overcome this problem is to further develop the seeming advances of the analytical room by storing the e-mail in a more rational way. First, storing your e-mail makes it possible to get control. It becomes easy to pick up relevant addresses, and with just a glance find out to whom in the network it is worth spending time to send an e-mail. Thanks to the structure, it becomes quick to find the right e-mail and people who will answer your e-mail. The logic seems clear. But does it work properly in practice?

Mackay (1988) gives us an example that can be fruitful to highlight this phenomenon. Mackay tells us about an ordinary e-mail user who had 600 messages in his inbox and 40 folders. The stored messages were a mix of correspondence with personal friends, information "that may be useful some day," messages that required some kind of action from the archivist's side, and unseen messages. He expressed his unwillingness to delete messages by asking, "What percent of the ocean don't you like?" We can ask the question why it is so important to store old memos. Cooper (1993, p. 270) gives us one suggestion when he writes,

In remote control, representation displaces the outside of the remote and "beyond" into the inside of the near and familiar. In abbreviation, it displaces the outside of the dispersed and macroscopic into the inside of the compact and manageable.

The user in Mackay's example does not say, "What percent of the quantity of your colleagues' messages don't you like (and which seems easier to accept to delete)?" He inverses the familiar to the outside, the dispersed and macroscopic. He does not see a picture of a lot of e-mail, a lot of information, from the outside. The big and the small become interchangeable, the representational coding has been broken with proportionality and has taken precedence over the event it represents. The representation gives a selective and discriminatory picture of the world (see Kallinikos 1996). My point is that what I have called the dividing principle, which maintains an analytical space, here seems to take a twist.

All e-mail can be stored in the computer. The techniques can differ. In the macroscopic, this stored e-mail is nothing, but seems to become important in the representation process of displacement. The e-mail one has received has become 
near and familiar. But it belong to the network world. Users will not harm one bit of themselves through deleting the old e-mail. "The stored e-mail can be useful, sometimes," is a frequent answer in my empirical material too.

Research - as well as my interviewees - shows that most of the users using e-mail do not use the grand thought presented above: "Abbreviated representation of the world in classes and names, enables the e-mail users to see more clearly and more quickly." E-mail users rather let most of their e-mail be kept in the in-box or maybe in the trash bin (see Mackay 1988; Whittaker and Sidner 1996). They have instead an aversion to organizing their e-mail in this folderdirection. This aversion seems not primarily linked to technical problems, but to the way they have to handle their e-mail. Simply, the users point at the difficulties of reaching a proper taxonomy. As three people from the insurance company responded when I focused my questions on this phenomenon:

I find it good to have all my e-mail in the inbox. When I scroll the inbox all the e-mail works as a reminder for me. If I had put some of the e-mail in another directory, I would not have had this opportunity. As long as my e-mail is in the in-box I read it and I will get reminders all the time.

I do not use different directories very frequently. When the email no longer seems relevant I trash them; all the others I keep in my inbox, which I try to keep as small as possible. I will see directly what is important or not, my e-mail in the inbox has life in this way.

My inbox is a kind of my to-do list. All e-mail in my inbox is something I have to deal with. And they will always remind me about it...I don't have to work in such a structured order as I would if I saved all my e-mail in different boxes.

We can here see how the displacement of information is a much more complex phenomenon than just packing, dividing information in a convenient way. The practice of having one inbox where almost all e-mail is stored (until they are deleted) gives the feeling of their actuality. To divide e-mail in different folders is for many of the interviewees to "kill" the e-mail, and thereby to some degree to forget them. From my interviews at the insurance company, no one said they organized their e-mail in different directories. The users stress how difficult it is to remember where they have put certain e-mail to maintain a balance between different folders. Some folders will become too big and some too small. Parallel to the dominating discourse around e-mail belonging to the analytical space, there seems to be a discourse that apparently does not prioritize 
an analytical space with a corresponding gaze. It is rather a space where glance, spontaneity, experimenting-by-doing, senses, a process of rendering the visible expressible in immediate terms which are at hand. A kind of sensory knowledge of the simultaneous combination of seeing, experimenting, conceiving, and saying, as a form of discipline beside the analytical one. What we may be able to glimpse, due to the large amount of incoming e-mail, is the character of another discipline with its own possibilities and problems.

\section{CONCLUDING REMARKS}

I have argued that the discourse around e-mail can be regarded as a result of disciplinary power linked to how information is represented in e-mail. The user that the disciplinary power has encompassed is the place for the articulation of a different discussion, the role of which is to normalize and master the unpredictable. To be active in an e-mail system is to have control of others members who are active or not, and to expand this control by the knowledge of making experiments. Who are the users to whom it is worth spending time sending email? The right thing in the right place is the formula of how information is represented in e-mail systems. The users can separate formal and informal email. The active users count qualities and merits and maintain a scheme of comparative order.

From this background, I have - among a number of different concepts - also illuminated another discourse around e-mail linked to the large number of e-mail circulating in the net. It can be seen as a syntactical reorganization of what email is all about, in which the limits and what is represented follow new patterns, where spontaneity, experimenting-by-doing, and senses come into focus. Briefly put: discursive practices that generate new knowledge. Whatever comes out of the analysis in this paper does not aspire to any closure, but maybe the beginning of a discussion on different discursive practices which could be linked to other discussions that seem just as possible as the analytical one.

\section{REFERENCES}

Alvesson, M., and Sköldberg, K. Reflexive Methodology: New Vistas for Qualitative Research. London: Sage, 2000.

Bell, D. The Coming of Post-Industrial Society: A Venture in Social Forecasting. London: Heinemann, 1974.

Bikson, T., Evelans, J., and Gutek, B. "Flexible Interactive Technologies for Multi-Person Tasks: Current Problems and Future Prospects," in N. Olson (ed.), Technological Support for Work Group Collaboration. Hillsdale, NJ: Erlbaum, 1989. 
Broms, H., and Gahmberg, H. "Communication to Self in Organization and Cultures," Administrative Science Quarterly (28), 1983, pp. 482-495.

Bälter, O. Electronic Mail in a Working Context, Unpublished Doctoral Dissertation, Royal Institute of Technology, Stockholm, Sweden, 1998.

Cecez-Kecmanovic, D., Modie, D., Busuttil, A., and Plesman, F. "Organizational Change Mediated by E-mail and Intranet," Information Technology \& People (12:1), 1999, pp. 9-26.

Chia, R. "The Problem of Reflexivity in Organizational Research: Towards a Postmodern Science of Organization," Organization (3:1), 1996, pp. 31-59.

Chia, R. Organized Worlds, London: Routledge, 1998.

Child, J., and Loveridge, R. Information Technology in European Services - Towards a Microelectronic Future. Oxford: Blackwell, 1990.

Clegg, S. "Foucault, Power and Organizations," in A. McKinlay and K. Starkey (eds.), Foucault, Management and Organization Theory. London: Sage, 1988.

Cooper, R. "Formal Organization as Representation: Remote Control, Displacement and Abbreviation," in M. Reed and M. Hughet (eds.), Rethinking Organization. London: Sage, 1992.

Cooper, R. "Technologies of Representation," in P. Ahonen (ed.), Tracing the Semiotic Boundaries of Politics. Berlin: de Gruyter, 1993.

Cross, R., and Baird, L. "Technology is Not Enough: Improving Performance by Building Organizational Memory," Sloan Management Review (41:3), 2000.

Davenport, T., and Prusak, L. Working Knowledge. Boston: Harvard Business School Press, 1998.

Deleuze, G. Foucault. Stockholm: Symposium, 1988.

Dreyfus, H., and Rabinow, P. Michel Foucault: Beyond Structuralism and Hermeneutics. Chicago: The University of Chicago Press, 1983.

Drucker, P. Management. New York: Harper \& Row, 1973.

Dubrovsky, V, Kiesler, S., and Sethna, B. "The Equalization Phenomenon: Status Effects in Computer-Mediated and Face-to-Face Decision-Making Groups," Human-Computer Interaction (6), 1991, pp. 119-146.

Eco, U., and Sebeok, T. The Sign of Three-Dupin, Holmes, Peirce Bloomington, IN: Indiana University Press, 1983.

Feldman, M. "Electronic Mail and Weak Ties in Organizations," Office: Technology and People (3), 1987, pp. 83-101.

Foucault, M. The Archaeology of Knowledge, New York: Pantheon, 1972.

Foucault, M. Discipline and Punish. London: Penguin, 1977.

Foucault, M. "The Discourse on Language," trans. Rupert Swyer, included as appendix to American Edition of The Archaeology of Knowledge, New York: Pantheon, 1971.

Foucault, M. Madness and Civilization. New York: Pantheon, 1965.

Foucault, M. The Order of Things: An Archaeology of the Human Sciences London: Tavistock Publications, 1966, reprinted 1970.

Goodman, N. Ways of Worldmaking. Indianapolis, IN: Hackett, 1978.

Gordon, C. Power/Knowledge: Selected Interviews and Other Writings 1972-1977. New York: Pantheon, 1980.

Habermas, J. Communication and Evolution of Society. Boston: Beacon Press, 1979.

Habermas, J. The Theory of Communicative Action. Boston: Beacon Press, 1984.

Hall, R. "How to Avoid Unwanted E-mail," Communications of the ACM(41:3), March 1998, pp. 88-95.

Hanson, N. R. Patterns of Discovery: An Inquiry into the foundations of Science Cambridge: Cambridge University Press, 1958.

Hiltz, S., and Turoff, M. The Network Nation: Human Communication via Computer. Reading, MA: Addison-Wesley, 1978. 
Hoy, D. Foucault: A Critical Reader. Oxford: Basil Blackwell, 1986.

Kallinikos, J. Technology and Society: Interdisciplinary Studies in Formal Organization. Munich: Accedo, 1996.

Kiesler, S. "Thinking Ahead. The Hidden Messages in Computer Networks," Harvard Business Review," January-February 1986, pp. 47-59.

Kiesler, S., Siegel, S., and McGuire, T. W. "Social Psychological Aspects of Computer-Mediated Communication," American Psychologist, October 1984.

Königer, P., and Janowitz, K. "Drowning in Information, but Thirsty for Knowledge," International Journal of Information Management (15:1), 1995, pp. 5-16.

Latour, B. Science in Action. Milton Keynes: Free Press, 1987.

Mackay, W. "Diversity in the Use of Electronic Mail: A Preliminary Inquiry," ACM Transactions on Office Information Systems (6:4), October 1988, pp. 380-397.

Malone, T., Grant, K., Turbak, F., and Cohen, M. "Intelligent Information Sharing Systems," Communications of the ACM (30:5), 1987, pp. 390-402.

Merquior, J. Foucault. Berkeley: University of California Press, 1985.

Motiwalla, L. "An Intelligent Agent for Prioritizing E-mail Messages," Information Resources Management Journal (8), 1995, pp. 16-24.

Nelson, R., and Winter, S. An Evolutionary Theory of Economic Change. Cambridge, MA: Harvard University Press, 1982.

Poster, M. The Mode of Information - Poststructuralism and Social Context. Oxford: Basil Blackwell, 1990.

Power, M. The Audit Society: Rituals of Verification. Oxford: Oxford University Press, 1997.

Rice, R. "Computer-Mediated Communication System Network Data: Theoretical Concerns and Empirical Examples," International Journal of Man-Machine Studies (32), 1990, pp. 627 647.

Romm, C, and Pliskin, N. "The Role of Charismatic Leadership in Diffusion and Implementation of E-mail," The Journal of Management Development (18:3), 1999, pp. 273-290.

Sheridan, A. Foucault-The Will to Truth. New York: Routledge, 1980.

Siegel, J. "Group Processes in Computer Mediated Communication," Organizational Behavior and Human Decision (37), 1986, pp. 157-187.

Sproull, L., and Kiesler, S. Connections-New Ways of Working in the Networked Organization. Cambridge, MA: MIT Press, 1991.

Stewart, T. A. Intellectual Capital: The New Wealth of Nations. New York: Currency Doubleday, 1997.

Whittaker, S., and Sidner, C. "Email Overload: Exploring Personal Information Management of Email," Proceedings of CHI'96 Conference on Computer Human Interaction, New York: ACM Press, 1996, pp. 276-283.

Zuboff, S. In the Age of the Smart Machine. New York: Basic Books, 1988.

\section{About the Author}

Mats Edenius is an assistant professor at the Center for Information and Communications Research (CIC) at Stockholm School of Economics. He received his Ph.D. in 1996 from Stockholm University. Mats is the program director of e-management at CIS. His research interests lie within the area of information technology and management. Mats can be reached by e-mail at dme@hhs.se. 